\title{
Scanning Electron Microscopic Time-lapse Visualization of Ash Movement During Regeneration of Diesel Particulate Filters
}

\author{
Sattatad Rodvanna ${ }^{\text {1) }}$ Mek Srilomsak ${ }^{\text {1) }}$ Mitsuhiro Shinshi ${ }^{1)}$ Katsunori Hanamura ${ }^{1)}$ \\ 1) Tokyo Institute of Technology (2-12-1 Ookayama, Meguro-ku, Tokyo 152-8550, Japan)
}

\begin{abstract}
A movement and oxidation behaviors of ash during partial oxidation of particulate matters (PMs) was investigated through time-lapse visualization utilizing a field-emission scanning electron microscope and thermogravimetric analysis (TGA). The fine primary ash particles consisted of elements such as zinc and phosphorus. The components of calcium, zinc, phosphorus, and sulfur were included in the large-scale ash particles. These ash particles were gradually moved as the PMs Cake layer shrunk during the regeneration of diesel particulate filters. In addition, ash particles distributed in PMs cake layer have contributed to an enhancement of oxidation rate of the PMs.
\end{abstract}

Received on December 12, 2019

KEY WORDS:Heat engine, Particulate filter, Emissions gas, Ash deposition, Time-lapse visualization (A1)

\section{Introduction}

Vehicle exhaust regulations has been strengthening year by year. Particulate matterd (PMs) emitted from diesel exhaust gases must be treated via after-treatment systems to protect human health and environment. Diesel particulate matters are composed of solid and liquid fraction such as unburned hydrocarbon (soot) and metal oxide ashes. A liquid fraction usually refers to a soluble and volatile organic fraction, SOF and VOF, respectively ${ }^{(1)}$. The metal oxide ashes are incombustible material mainly derived from lubricant additives. The role of these lubricant additives ${ }^{(2)}$ are to improve a performance of engine oil such as rust and corrosion inhibitors, anti-oxidants, anti-wear, and viscosity index modifiers. Diesel after-treatment systems comprise of many instruments such as diesel oxidation catalysts (DOCs), diesel particulate filters (DPFs), selective catalytic reductions (SCRs) and ammonia oxidation catalysts (AOCs). Among these instruments, utilizing DPFs are the most effective way to reduce the emission of PM. Soot can be trapped with high filtration efficiency and burnt through the regeneration process. However, the unburned metal oxide ashes will remain and deposit along the filter length causing a high engine back pressure. Therefore, a performance relates to filtration efficiency and pressure drop depend on amount of ash deposition. There are two types of ash deposition: wall ash ${ }^{(3)}$ and plug ash ${ }^{(4)}$. Wall ash covers the DPF wall and performs as a membrane filter resulting in a high filtration efficiency. When there is a proper amount of deposited wall ash, it can be removed by the fluid-dynamical shear force and accumulated at the end of DPF channel as the plug ash ${ }^{(5)}$. Plug ash completely fills the channel and reduces the effective length of the filter ${ }^{(6)}$, causing a large pressure drop which reduce the efficiency of Diesel engines. To maintain a high working performance of DPF, the mobility of ash should be investigated simultaneously with the deposition and oxidation processes of PM.

Recently, the agglomeration and growth of ash during a regeneration of DPF was investigated by the authors through timelapse visualization utilizing a field-emission scanning electron microscope (FESEM) and energy dispersive X-ray spectroscopy $(\mathrm{EDS})^{(7)}$. From this visualization, it was confirmed that PM cake layer was oxidized and broken down during the regeneration. This cause ash particles contacted each other and sintered. After oxidation process was completed, various types of ash particles were produced. However, the oxidation was completed too early in only one time-lapse image (15 sec.). As a result, a movement of ash particles during regeneration still unclear. In addition, it was hypothesized that the early completion of oxidation was due to a high reactivity of soot sample when ash was contained.

In this study, the movement of ash particles was clarified using time-lapse visualization method. The oxidation behaviors and elemental compositions of two different types PMs samples were investigated through thermogravimetric analysis (TGA) and a scanning transmission electron microscope (STEM).

\section{Experiments}

In this study, the experiments were divided into two parts:

1. TGA and characterization of PMs

2. Time-lapse visualization of ash movement during regeneration of diesel particulate filters 
Vol.11, No.2(2020)

\section{TGA AND CHARACTERIZATION OF PMs}

\section{Thermogravimetric analysis (TGA)}

The PM sample powder, consists of pure soot and soot with 11 wt. $\%$ ash components ( soot/ash $=8$ ), were analyzed their oxidation behaviors using a thermogravimetric analyzer (Shimadzu DTG60). Approximately $3 \mathrm{mg}$. of each sample and the total gas flow rate of $30 \mathrm{ml} / \mathrm{min}$ were conducted in this experiment. In a preheating process, the sample was heated up from room temperature with pure nitrogen gas at the increasing rate of $20^{\circ} \mathrm{C}$ until reaching the target temperature of $600^{\circ} \mathrm{C}$. Then, the sample was oxidized isothermally with the $10 \% \mathrm{O}_{2}$ working gas conditions. This condition was simulated as a practical active regeneration of DPF and it was similar to the time-lapse regeneration experiment. A remaining mass curve versus time were obtained at one second interval.

\section{Organic elemental composition analysis}

A Vario EL Cube organic element analyzer was used to analyze components of carbon $(\mathrm{C})$, hydrogen $(\mathrm{H})$, nitrogen $(\mathrm{N})$, oxygen $(\mathrm{O})$ and sulfur (S). Each PM sample was weighted approximately 10 mg. in the vessels and loaded into the instrument. The samples were flushed with carrier gas such as helium and Argon to remove atmospheric nitrogen. The catalytic combustion is carried out at a temperature of $1150^{\circ} \mathrm{C}$. Then, the combustion gas was separated into three columns by the well proven purge, chromatography and also fed into a thermal conductivity detector (TCD). The mass percentage of each species were determined by the element concentration from the detector signals. The remaining unknown species was stated as ash. In addition, the Vario micro cube was used to analyze oxygen contents separately from $\mathrm{C}, \mathrm{H}, \mathrm{N}$ and $\mathrm{S}$.

\section{Scanning Transmission electron microscopy (STEM)}

A scanning transmission electron microscopy (STEM) images were made by using a transmission electron microscope (JEM2100F) also equipped with and Energy Dispersive X-ray Spectrometry (JED-2300T, diameter $30 \mathrm{~mm}^{2}$ ). PM sample was dispersed in a carbon tetrachloride solution $\left(\mathrm{CCl}_{4}\right)$ and dropped onto the $\mathrm{Cu}$ microgrid to dry naturally. The instrument was operated at acceleration voltage $200 \mathrm{kV}, 15-20$ images of ash samples were surveying for estimation of particle diameter, as well as analyzed their components.

\section{Thermo mass/mass spectrometer system (TG-DTA/MS)}

A desorption of oxygen from surface of ash particle was measured by thermo mass/mass spectrometer system (Rigaku). The experiment was conducted with approximately $14 \mathrm{mg}$. of ash powder. The sample was heated under helium inert gas from room temperature to $1000{ }^{\circ} \mathrm{C}$ at heating rate of $20{ }^{\circ} \mathrm{C} / \mathrm{min}$. The gases evolved in response to the sample heated were ionized and analyzed using accelerated electron with $70 \mathrm{eV}$, and quadruple type mass detector, respectively.

\section{TIME-LAPSE VISUALIZATION OF ASH MOVEMENT DURING REGENERATION OF DIESEL PARTICULATE FILTERS}

\section{Experimental setup}

Figure 1 presents a preparation of small DPF sample and holder for visualization. The small size DPF was cut $10 \times 10 \times$ $10 \mathrm{~mm}^{3}$ and it was comprised of a $7 \times 7$ channel matrix. Its channels were alternately plugged at each end by a ceramic paste. Then, it was put into DPF holder, made of stainless steel, and ceramic paste was used to seal around DPF sample and holder. In order to visualize the cross-sectional vertical wall of the DPF, the horizontal top wall was removed ${ }^{(8,9)}$. The top surfaces of the vertical walls and the holder were polished simultaneously and uniformly utilizing abrasive papers with grit sizes ranging from P240 to P4000. After the mirror-like polishing, the open channels were covered by a quartz glass plate to replace the removed horizontal wall. After trapping and each partial oxidation, crosssectional images of the vertical wall between the open channels were obtained by utilizing an FESEM (JEOL, JSM-6301F with a resolution of $1.5 \mathrm{~nm}$. at $2 \mathrm{KeV}$ )

\section{Experimental procedures}

Figure 2 presents a schematic of the diesel particulate generator (DPG). Diesel Particulate Generator (DPG) was utilized to produce soot with ash components and introduced to the actual full-size DPF which is simulate the actual DPF system presents in the automobile. The total flow rate and PM loading ratio was controlled by the main combustor based on the primary, secondary, and tertiary air supplies. Ash elements were introduced via spray combustion utilizing an oil injector with element concentrations shown in table 1 .
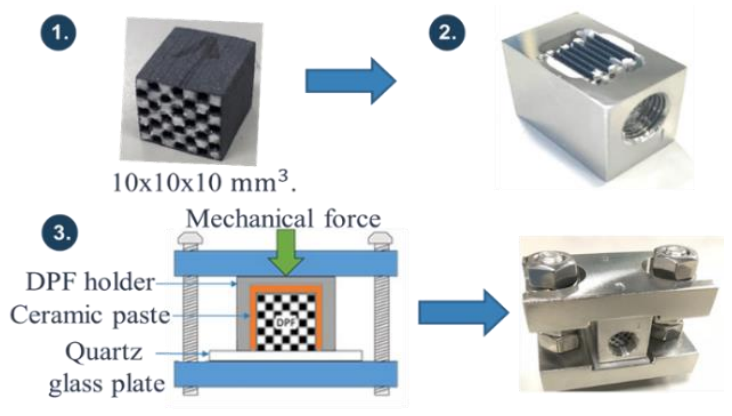

Fig. 1 Preparation of DPF sample 
Vol.11, No.2(2020)

As a result, the PM included ash with a weight ratio of $11 \mathrm{wt} . \%$. The main combustion gas consisting of PM and ash was then introduced into a DOC and full-size DPF. Additionally, in this study, a small amount of the combustion gas was bypassed at the location between the DOC and DPF.

Figure 3 presents a schematic of the trapping experiment to introduce soot with ash to the small DPF sample. The flow rate of the bypass line was controlled and measured by a suction pump and mass flow controller on the downstream side of the DPF. The pressure drop was measured across the filter to ensure a proper thickness of PMs cake layer. The small DPF was kept at a constant temperature of $150{ }^{\circ} \mathrm{C}$ for 4 hours PM loading. In this case, the space velocity ratios for both DPFs were fixed at 60,000 h-1 and the superficial velocities for wall flows in the main line and bypass line were 26.4 and $28.2 \mathrm{~mm} / \mathrm{s}$, respectively. As a result, the mass of loading ratios of soot (mainly carbon) and ash were nearly the same for both full and small size DPFs, as shown in Table 2.

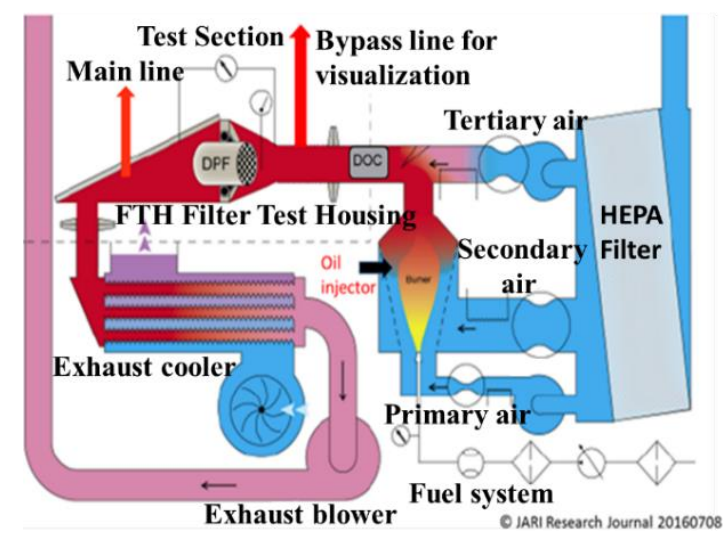

Fig. 2 Schematic of the DPG

Table 1 Concentrations of ash elements introduced to DPG

\begin{tabular}{|c|c|}
\hline Ash Elements & Oil injector Concentrations (wt.\%) \\
\hline Calcium & 0.5 \\
\hline Phosphorous & 0.4 \\
\hline Zinc & 0.4 \\
\hline Sulfur & 0.8 \\
\hline
\end{tabular}

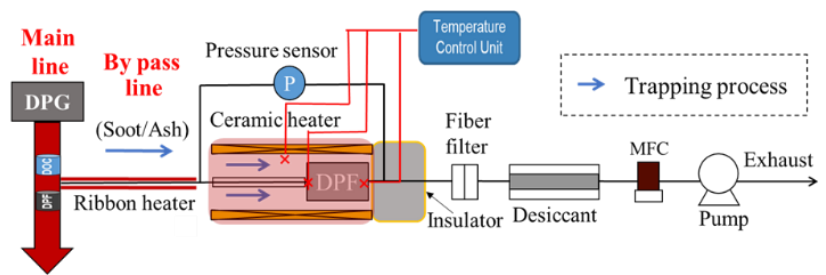

Fig. 3 Schematic of a bypass line for the trapping experiment.
Figure 4 presents a schematic of regeneration process. The mass flow controllers were installed on the upstream side of DPF to introduce a proper flow rate of nitrogen and oxygen gas as the working gases for regeneration. An insulator was installed at the end of ceramic heater, to prevent a temperature gradient. Three thermocouples were used to control and monitor the temperature of the ceramic heater, as well as measure temperature at the upstream and downstream sides of DPF. The working gas cooling unit and gas analyzer (Shimadzu CGT-7100) were connected at the downstream side to reduce a temperature of working gas and to analyze the concentration of carbon monoxide (CO) and carbon dioxide $\left(\mathrm{CO}_{2}\right)$, respectively.

Figure 5 presents the experimental procedures for time-lapse visualization. In order to remove an effect of decorated oxide component, a pre-treatment which is heating up and cooling down was conducted before time-lapse experiment. A pure nitrogen was used during heating up as a working gas to prevent a pre-oxidation of PM. When a temperature reaches $600^{\circ} \mathrm{C}$, immediately, the DPF sample was cooled down naturally to a room temperature. For the regeneration experiment (figure 5), as a temperature reaches $600{ }^{\circ} \mathrm{C}$, the working gas was switched from pure nitrogen to $10 \%$ oxygen. The PM was oxidized at a temperature of $600{ }^{\circ} \mathrm{C}$ for 2 seconds (No.2 in fig.5). Then, the working gas was quickly switched back to nitrogen, to impede the oxidation and cool down to a room temperature (No.3 in fig.5). The DPF sample was carefully removed from the DPF holder and the cross-sectional walls were visualized by utilizing a FESEM (No.4 in fig.5). This constitutes the first time-lapse visualization. By utilizing the same open-channel DPF, as well as the same observing spots, these processes were repeated, create a time-lapse image.

Table 2 Experimental conditions for main line and bypass line

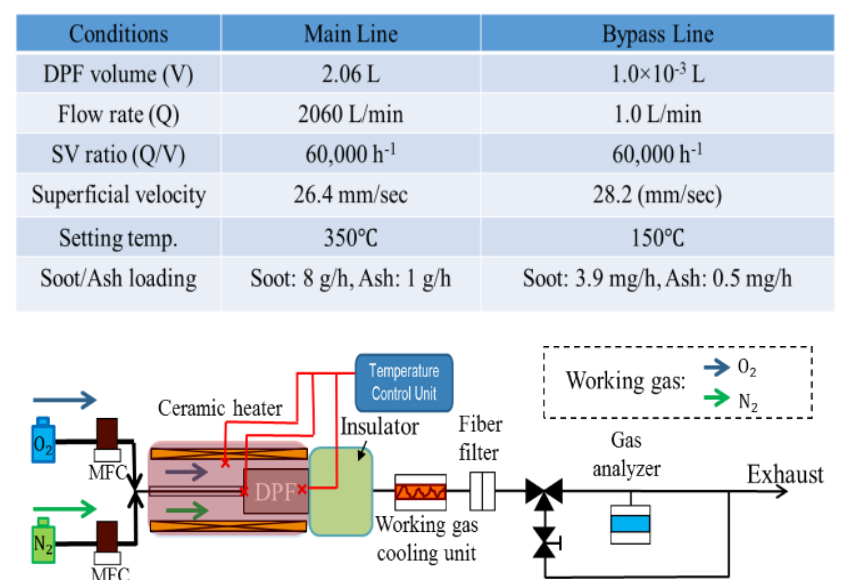

Fig. 4 Schematic of regeneration processes 
Vol.11, No.2(2020)

\section{Results and discussion}

\subsection{TGA results}

Figure 6(a) presents TGA results of soot and soot with $11 \%$ ash. The horizontal axis represent time in minutes, on the left and right vertical axis represent mass $(\%)$ and temperature $\left({ }^{\circ} \mathrm{C}\right)$, respectively. The mass (\%) was directly converted to mass reduction rate versus time (min.) as shown in figure 6(b). During heating up process with pure nitrogen, mass losses were observed on both samples. A mass of soot has remained almost $100 \%$ during heating from $25^{\circ} \mathrm{C}$ to about $500^{\circ} \mathrm{C}$, after that, it started to decrease until reached about $90 \%$ mass at $600^{\circ} \mathrm{C}$. On the other hand, soot with $11 \%$ ash started to have a sharp decreased of mass at temperature of $400^{\circ} \mathrm{C}$ and it continuously decreased until reached $70 \%$ mass or had $30 \%$ mass loss at $600^{\circ} \mathrm{C}$. In addition, the mass reduction rate of soot with $11 \%$ ash was about two times higher than pure soot just after an introduction of $10 \% 0_{2}$ for oxidation. As a result, an oxidation of soot with $11 \%$ ash was completed almost 50 minutes earlier than pure soot while $11 \%$ of residual mass was remained as indicated on a concentration of ash particle.

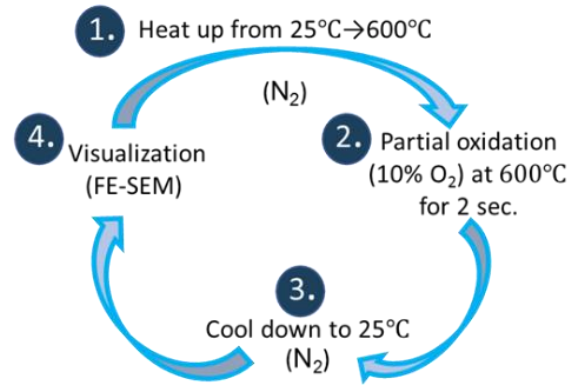

Fig.5 Schematic of experimental procedures

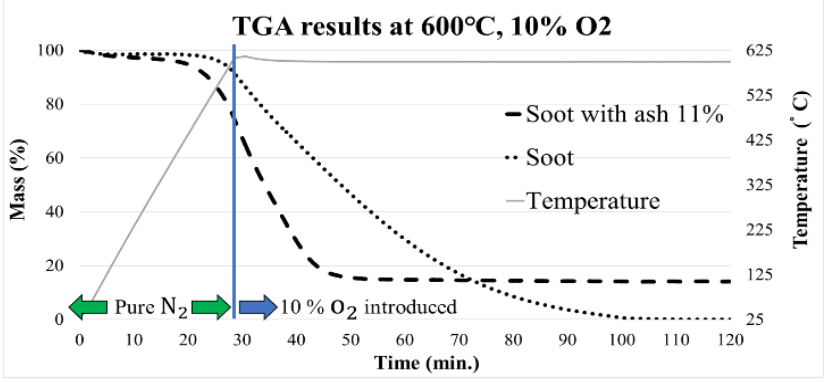

(a)

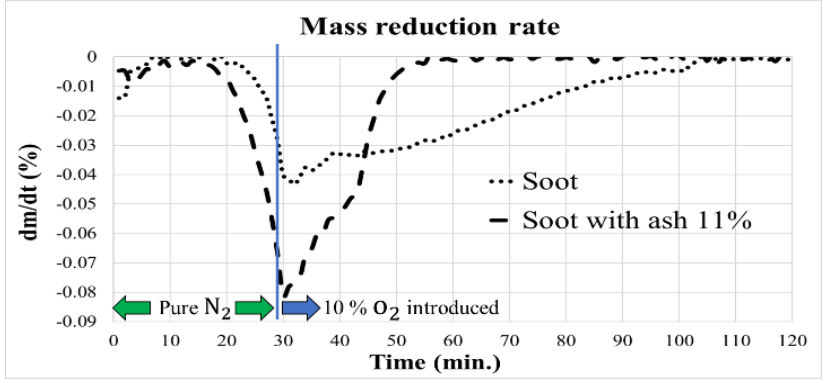

(b)

Figure 6. presents TGA results of mass \% (a) and mass reduction rate (b).
The oxide of ash particles which are in the form such as oxides (-O), sulfates (-SO4), and phosphates(-PO4) may perform as the additional source of oxygen that promote soot oxidation. Since pure soot also had a mass loss during heating under inert gas $\left(\mathrm{N}_{2}\right)$, this mass loss can be a product of oxidation between carbon and decorated oxygen atoms, as well as volatile organic compounds (VOC) and soluble organic fraction (SOF).

In order to verify this result, each PM powder was collected and analyzed using organic elemental composition analysis as shown in the next section.

\subsection{Organic elemental composition}

Table 3 presents the percent weight ratio of PM composition used in this study. Pure soot had the highest composition of $\mathrm{C}$, while compositions of $\mathrm{H}$ and $\mathrm{N}$ from both samples were similar. The oxygen atom components of soot with $11 \%$ ash cannot be analyzed from the elemental analyzer due to its higher ash contents than 5\%. Therefore, it was indicated as N/A. However, more than $10 \%$ of undetermined composition of soot with $11 \%$ ash might consists of $\mathrm{O}$. As a result, soot with $11 \%$ ash had higher $\mathrm{O}$ atom than pure soot. This higher $\mathrm{O}$ atom may cause partially oxidized the $\mathrm{C}$ component during preheating, as well as accelerated oxidation reaction. Although an engine oil injector was not utilized, about $2 \%$ of ash contents in pure soot was found. This small amount of ash components might come from the accumulated or a wear and tear of the DPG pipeline. On the other hand, a percentage of ash contains in the case of soot with $11 \%$ ash was quite precise as indicated at $11 \%$ concentrations. Even though sulfur element, consists in the injected oil, had the highest concentration as shown in Table 1 , only about $0.45 \%$ of sulfur contains in the total $10.5 \%$ ash. This amount of sulfur was almost 2 times less than the injected amount ( 0.8 wt.\%). The engine oil was injected into the combustion chamber and pass through the mainline at $350^{\circ} \mathrm{C}$ which almost exceed the saturation point, therefore, much amount of Sulfur may evaporate or sintered with other components. Beside the sulfur components, other ash components were not further analyzed.

Table 3. presents organic elemental composition of pure soot and soot with $11 \%$ ash.

\begin{tabular}{|c|c|c|}
\hline & Soot & $11 \%$ ash \\
\hline C [\%] & 88.85 & 74.49 \\
\hline H [\%] & 0.71 & 0.98 \\
\hline N [\%] & 0.15 & 0.17 \\
\hline O [\%] & 8.17 & N/A \\
\hline Total ash [\%] & 2.1 & 10.5 \\
\hline S & N/A & 0.45 \\
\hline Total [\%] & 99.98 & 86.14 \\
\hline
\end{tabular}




\section{Sattatad Rodvanna et al / International Journal of Automotive Engineering}

Vol.11, No.2(2020)

The ash components distributed on soot cake was investigated utilizing STEM with EDS mapping as shown in the following section.

\subsection{STEM and TEM images before regeneration}

Figure 7 presents bright field STEM image, as well as elemental analysis mappings. In the left image, large ash particles with an approximately $60 \mathrm{~nm}$. in diameter located in the soot cake as shown. From the mappings, signals of ash components such as $\mathrm{P}, \mathrm{Ca}, \mathrm{Zn}$ and $\mathrm{S}$ were concentrated on this large ash particle. In addition, the signals of primary ash particles which have a diameter range from 10 to $20 \mathrm{~nm}$. distributed in the soot particles could be detected within this bright field STEM images as indicated by white and red arrows. The signal of their components can be detected at the same location as shown in the elemental mappings. The $\mathrm{O}$ signal can be observed as it was distributed all over the soot cake and clearly it can be clarified that the signals highly concentrated on the ash particles rather than soot. The ash primary particles were further investigated through STEM with EDS spot analysis as shown in figures 8 .

Figure 8 presents STEM image and elemental analysis of ash components in carbon soot particle. Ash particles dispersed in soot cake layer as a dark nearly spherical-like shaped with various particle sizes. There were three different locations observed within this image, depicted by blue rectangular and labeled with numbers from 1 to 3 . The first observation area presents small size ash particle with $20 \mathrm{~nm}$. in diameter. From elemental analysis, this ash particle consists mainly of $\mathrm{Zn}$ and $\mathrm{P}$. The signals of other ash components such as $\mathrm{S}$ and $\mathrm{Ca}$ were negligibly small. The high intensity signals of $\mathrm{C}$ and $\mathrm{O}$ can also be clearly detected as this ash particle was in the soot cake. The second area presents particle with approximately $40 \mathrm{~nm}$. in diameter. The signals of all introduced ash elements $(\mathrm{Ca}, \mathrm{S}, \mathrm{Zn}$, and $\mathrm{P})$ were detected as shown in the elemental analysis. The third location was conducted as a reference when ash was absent, only the signal of $\mathrm{C}$ and $\mathrm{O}$ can be detected in a soot particle.

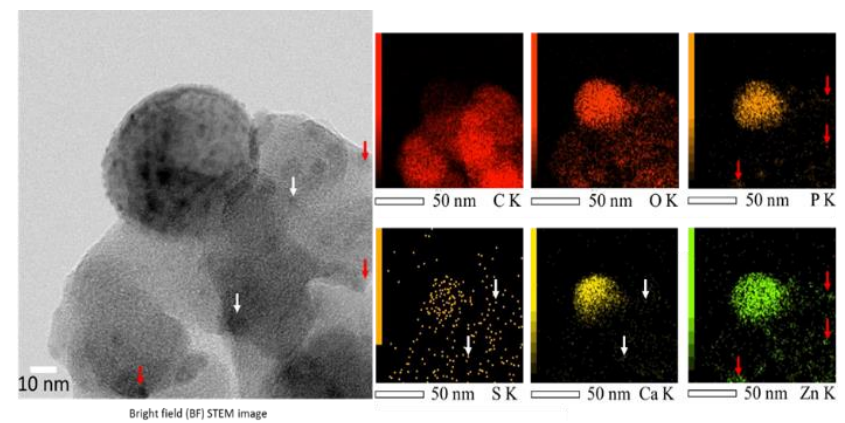

Figure 7 presents bright field STEM image, and elemental analysis mappings of ash components after trapping experiment.
Although oxygen signals cannot be identified whether they were on a surface of ash particle or mainly the components of themselves, the oxygen atoms can be clarified that they were distributed in a soot cake, as well as highly concentrated on large ash particles.

To precisely determine particle size and composition of ash, more sample were further investigated, and it was found that some others small size ash particles with a diameter of $20 \mathrm{~nm}$. consists also the sulfur and calcium components as shown in a dark field (DF) STEM image in fig.9. Therefore, it can be concluded that primary ash particles with a diameter smaller than $20 \mathrm{~nm}$. will have components of $\mathrm{Zn}$ and P. For bigger than $20 \mathrm{~nm}$. ash particles, they will consist of all ash components ( $\mathrm{Ca}, \mathrm{S}, \mathrm{Zn}$, and $\mathrm{P})$.

\subsection{Desorption of oxygen from a surface of ash particles}

To further investigate how ash particles influence on soot oxidation, the ash powder was collected from the regeneration of full-size DPF. Then, oxygen was adsorbed into this ash powder by using TGA at $600{ }^{\circ} \mathrm{C}$ in an isothermal condition for 1 hour at the condition of $10 \%$ oxygen concentrations. The same ash sample powder was measured the desorption of oxygen using TGDTA/MS. Figure 10 presents intensity of oxygen in gas phase, desorbed from ash sample. The vertical axis presents an intensity of oxygen while horizontal axis presents temperature in degrees Celsius. At $27^{\circ} \mathrm{C}$ room temperature, the signal of oxygen can be detected as it continuously decreased and disappeared around $430^{\circ} \mathrm{C}$.

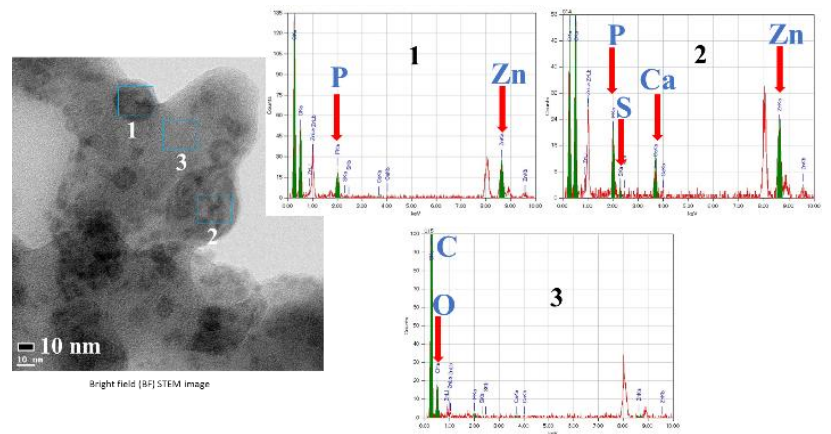

Figure 8 presents bright field STEM image and elemental analysis of ash components distributed in soot cake layer
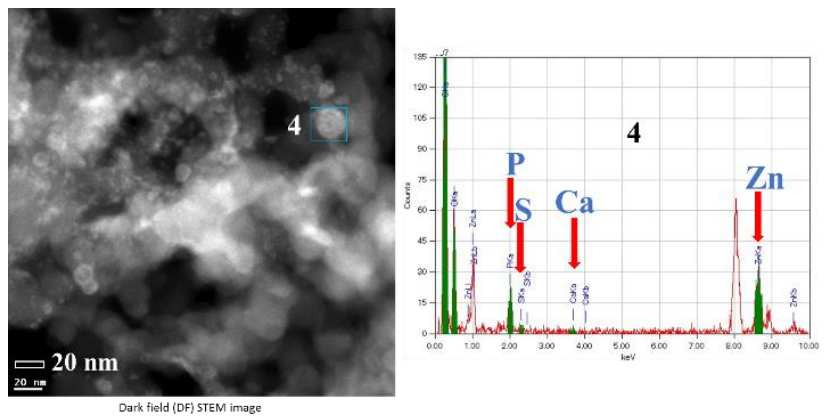

Figure 9 presents $20 \mathrm{~nm}$. ash particle consists of all components. 


\section{Sattatad Rodvanna et al / International Journal of Automotive Engineering}

Vol.11, No.2(2020)

This low temperature signal came from the air that partially entered the ionization chamber. On the other hand, the sharp increase of oxygen signal simultaneously with a mass loss at a high temperature $\left(>750^{\circ} \mathrm{C}\right)$ were the result of structure' $\mathrm{s}$ deformation. Both signals were not the result of oxygen desorbed from a surface of ash particle, therefore, they were depicted as grey line.

Focusing on the red line corresponding with a temperature from 500 to $600{ }^{\circ} \mathrm{C}$, the signal of desorbed oxygen can be detected around $500{ }^{\circ} \mathrm{C}$, and it continuously increased and remained constant at $600{ }^{\circ} \mathrm{C}$. Therefore, at $600{ }^{\circ} \mathrm{C}$ there were a desorption of oxygen from surface of ash particles. By making a comparison with a previous TGA result at the same temperature $600{ }^{\circ} \mathrm{C}$, there were a mass loss on both pure soot and soot with $11 \%$ ash during the preheating. A difference of a mass loss between these two samples is a result of the oxygen desorbed from a surface of ash particles causing a partial oxidized of soot and they also help accelerated and promoted soot oxidation. As a result, Soot with $11 \%$ ash exhibited higher mass loss than pure soot in any time intervals. In a practical DPF trapping process, oxygen has already absorbed on the surface of ash due to a high combustion temperature. Then, this oxygen will be desorbed resulting in an oxidation enhancement during DPF regeneration.

3.4 Time-lapse Visualization of ash movement during regeneration

Figure 11(a) presents FESEM image at a cross-sectional view just after PM was trapped into small size DPF. Figure 11(b) presents backscatters electron image at the same location. The backscatter electron image is used to detect the different elements present in a soot cake layer. The large ash components with higher atomic weight will have stronger scatters of electrons compared to light atoms, and thus create a higher signal intensity (white dots). Therefore, the dark area represents soot cake layer while white dots that distribute all over in the soot cake layer can represent large ash particles.

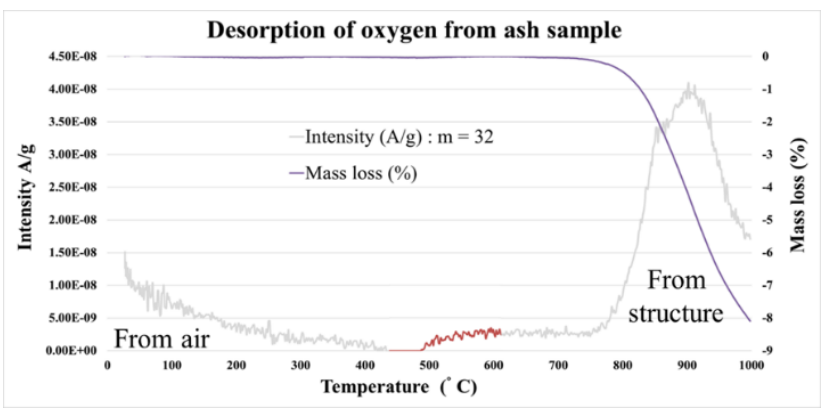

Figure 10 Intensity of oxygen desorbed from ash sample
Figure 11(c) and 11(d), present FESEM and backscatter images exactly the same location after this sample was heated up with pure nitrogen gas from room temperature to $600{ }^{\circ} \mathrm{C}$ and then immediately cooled down to room temperature. By making a comparison of FESEM images figure 11(a) with 11(c), the soot cake layer on the DPF Si-C wall drastically decreased during just heating up and cooling down due to an effect of decorated oxide components. In addition, a shrinkage of PM cake layer towards the SI-C DPF substrate can be clearly observed in the deeper area of a soot cake layer. In figure 11(a), the tracer areas and some small cracks were indicated by white arrows, however, these tracer areas disappeared, and cracks became closer, as shown in figure 11(c). This shrinkage can be the cause of a mass loss during heating up process of TGA discussed in section (3.1).

The red arrows in figure 11(b) and 11(d) indicated position of a tracer particle. It can be clearly seen that tracer particle moving in a direction toward the DPF SiC grains, as well as moved closer to other particles. On the other hand, ash particles located around the surface pores area did not move so much.

Figure 12 presents the cross-sectional FESEM time-lapse images of ash during a partial oxidation. The time interval indicated on each image is the cumulative time of partial oxidation. After a PM cake layer was partial oxidized at $600^{\circ} \mathrm{C}$ for only $2 \mathrm{sec}$., the soot cake layer continuously shrunk and a separation between soot cake and $\mathrm{SiC}$ grains can be clearly observed. A previous study ${ }^{(10)}$ on a comparison of arc generated soot with diesel practical soot using time-lapse regeneration method suggested that soot shrinkage occurred in three dimensions.

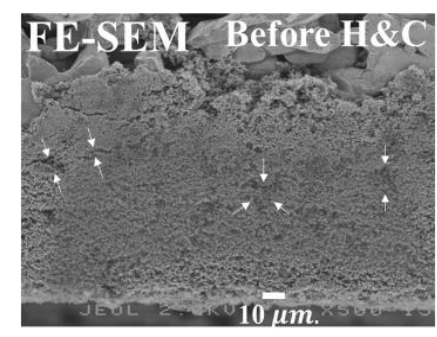

(a)

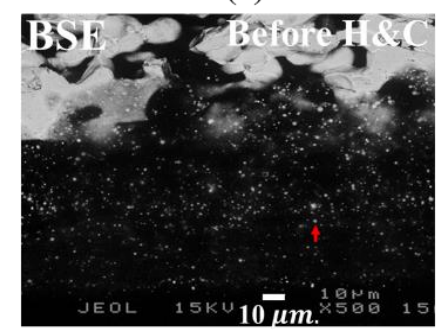

(b)

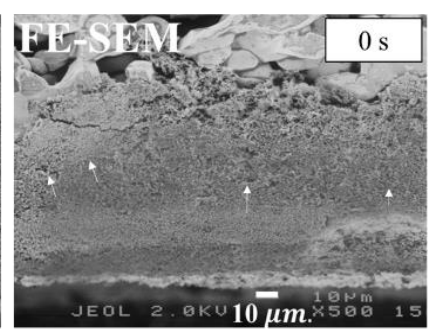

(c)

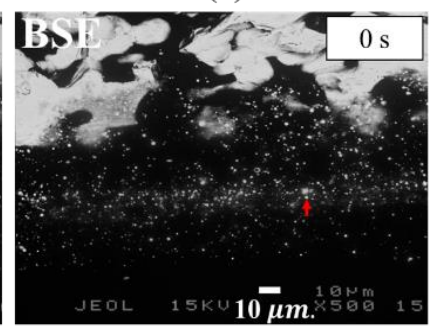

(d)
Figure 11 presents FESEM and backscatters electron images of small size DPF before and after ( 0 sec.) heating up and cooling down experiment 
A drag force from the working gas flowing in the normal direction to the cake layer together with a uniform shrinkage of primary particles from a homogeneously oxidation of $10 \%$ oxygen concentrations, initiated cracking of the remaining (thin) cake layer. In this study, same result can be observed as shown in this figure. Two cracks were observed along the depth of a soot cake layer. These cracks continuously expanded simultaneously with the shrinkage of the soot cake layer, after $4 \mathrm{sec}$. of partial oxidation as shown in the right image of figure 12 .

Figure 13 presents the backscatter electron (BSE) time-lapse visualization images of ash movement during regeneration from 0 to $4 \mathrm{sec}$. The movement, as well as agglomeration can be clearly seen. The white arrow and circle indicated ash tracer particles located in different locations. By observing ash particles located nearby the white arrow on figure 13 from left to right images orderly, ash particles were gradually moved and gathered together corresponding with an increasing of cumulative time. Another observing location was indicated by the white circle, two ash particles inside this circle initially located faraway from each other, then, they were moving closer and might be in contacted. If these two ash particles were in contacted, they will sinter and become large-scale ash particle.

By magnifying area between soot cake layer and surface pores of figure13, it can be clearly seen that the movement of ash particles depended on the shrinking direction of soot cake layer as shown in figure 14. The white arrows on images, indicated position of two tracer particles. After partial oxidation from 0 to 2 sec., tracer 1 located closer to the top soot cake layer, moved toward the $\mathrm{SiC}$ substrate to point $1^{\prime}$ in the middle image. Additionally, the same movement can be observed as this ash particle continue to move toward the SiC substrate to point 1", at $4 \mathrm{sec}$. as shown in the right image.
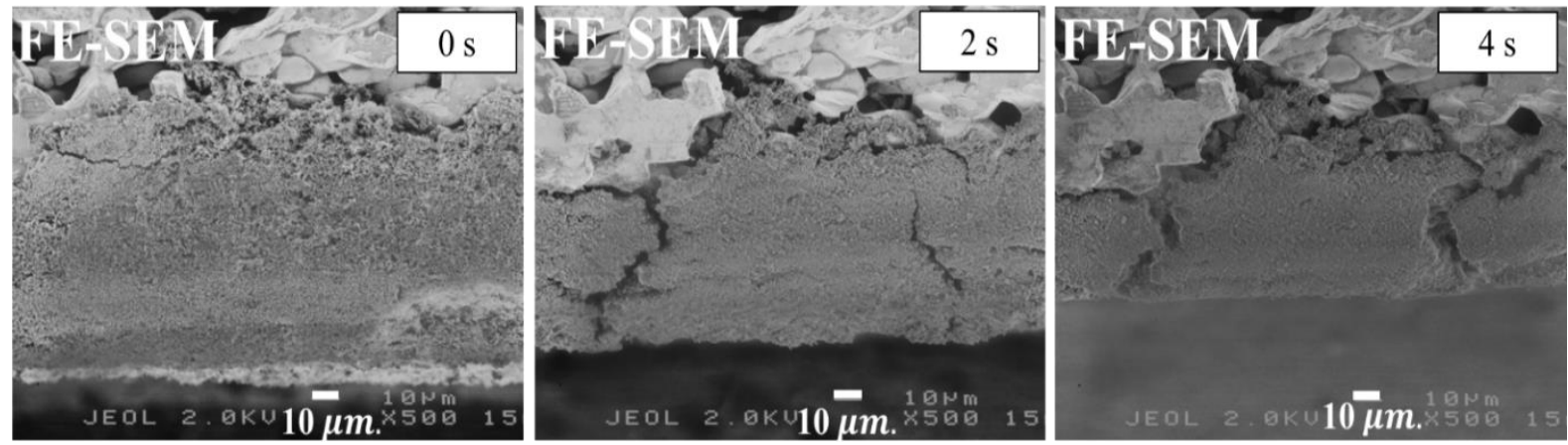

Figure 12 presents the cross-sectional backscatter electron (BSE) time-lapse visualization of ash movement during regeneration.
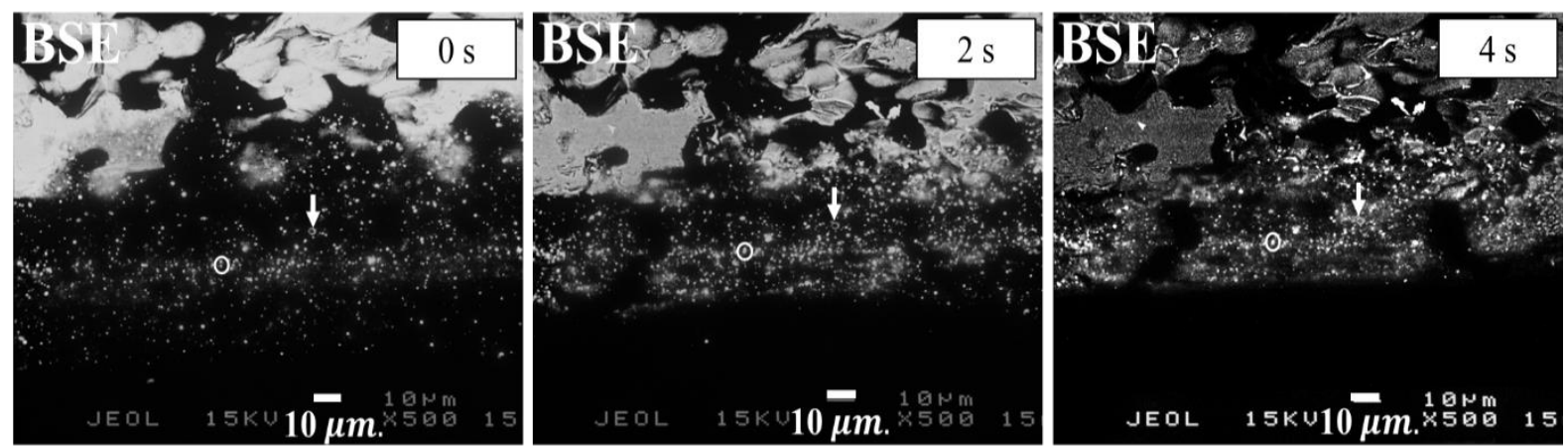

Figure 13 presents a higher magnification of cross-sectional backscatter electron (BSE) time-lapse images from 0 to 4 sec.
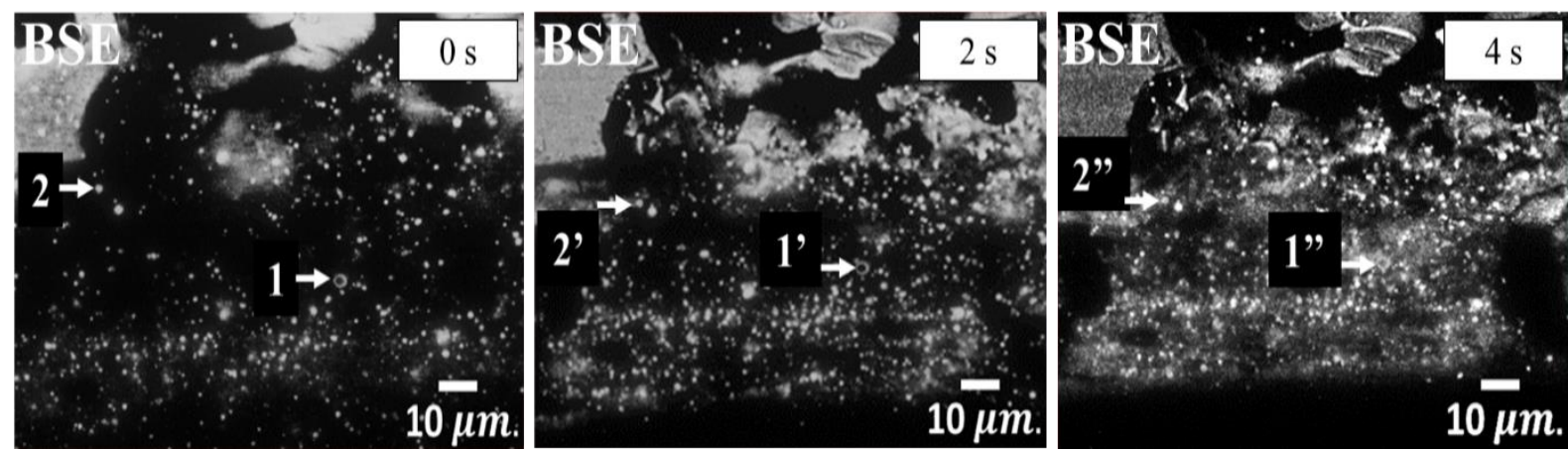

Figure 14 presents a higher magnification of cross-sectional backscatter electron (BSE) time-lapse images from 0 to 4 sec. 
On the other hand, tracers point 2 located closer to the $\mathrm{SiC}$ surface pores, moved away from $\mathrm{SiC}$ substrate to point 2'. However, tracer point 2" did not move so much since the shrinkage of soot cake at $4 \mathrm{sec}$. mostly taking place at the top soot layer. These differences in a movement direction of tracer 1 and tracer 2 come from the shrinkage of top soot cake layer that shrunk toward $\mathrm{SiC}$ grains and soot cake inside $\mathrm{SiC}$ surface pores that shrunk away from SiC grains, respectively. The same movement pattern will be repeated until soot is completely oxidized, tracer 1 and 2 will continuously move. Finally, they will deposited at the entrance of the surface pores.

\section{Conclusions}

The diesel soot and soot with $11 \%$ ash, derived from diesel particulate generator (DPG) were investigated their oxidation behaviors, as well as their elemental compositions utilizing TGA and STEM. All PMs samples had a mass loss during preheating with an inert gas $\left(\mathrm{N}_{2}\right)$. Moreover, soot with $11 \%$ ash also exhibits higher mass loss in any time intervals and its oxidation rate increased up to two times faster than a pure soot. This is due to decorated $\mathrm{O}$ atoms contained in carbon atoms and oxygen desorbed from a surface of ash particles that perform as an additional source of oxygen that accelerated the oxidation.

The time-lapse visualization of ash movement during regeneration process was conducted. Ash primary particles contained in a soot cake layer with a diameter range from 10 to 20 nm., consisted of zinc and phosphorus as main components. For larger ash particles, they consist of all ash components such as zinc, calcium, sulfur and phosphorus. Oxygen was highly concentrated on these ash particles. The movement of ash particles depended on a shrinking direction of a soot cake layer during a regeneration. As a soot cake shrunk, ash particles gradually moved and contacted with other ash particles. Depending on a location, ash particle that located inside the surface pores tend to move toward the entrance of it, while ash particle that located in the top soot cake layer moved toward the surface pores.

\section{Acknowledgments}

The authors would like to express their sincere appreciation for financial support from the Research Association of Automotive Internal Combustion Engines, technical support from the Japan Automobile Research Institute, field-emission scanning electron microscope from the analysis center of mechanical engineering, scanning transmission electron microscopy (STEM) and TGA instruments from the Suzukakedai materials Analysis Division of the Tokyo Institute of Technology.
This paper is written based on a proceeding presented at JSAE 2019 Autumn Congress

\section{References}

(1) P, Tornehed. And U, Olofsson : Lubricant ash particles in diesel engine exhaust, Journal of automobile engineering, Vol.225 Part D, (2011)

(2) Leslie, R. Rudnick. : Lubricant Additives: Chemistry and Applications, Third edition, Taylor \& Francis, (2017)

(3) Viswanathan, S., Rakovec, N., and Foster, D. : Microscale Study of Ash Accumulation Process in DPF Walls Using the Diesel Exhaust Filtration Analysis (DEFA) System, ASME, ICEF 2012-92104, (2012)

(4) Sappok, A., Wang, Y. et al. : Theoretical and Experimental Analysis of Ash Accumulation and Mobility in Ceramic Exhaust Particulate Filters and Potential for Improved Ash Management, SAE Technical paper, 2014-01-1517, (2014)

(5) Dittler, A. : Ash Transport in Diesel Particulate Filters, SAE Technical paper, 2012-01-1732, (2012)

(6) Sappok, A. : The Nature of Lubricant-Derived AshRelated Emissions and Their Impact on Diesel Aftertreatment System Performance, PhD Thesis, Massachusetts Institute of Technology, 2009.

(7) Rodvanna, S., Srilomsak, M., Mitsuhiro S., and Katsunori H.: Time-lapse Visualization of agglomeration and growth of ash during regeneration of Diesel Particulate Filter, JSAE proceedings Number: 20195139 May, 2019 Issued No.29-19

(8) Sanui, R. and Hanamura, K. : Electron Microscopic Time-lapse Visualization of Surface Pore Filtration on Particulate Matter Trapping Process, Journal of Microscopy, The Royal Microscopical Society, Vol. 263, No. 3, pp. 250-259, (2016)

(9) Sanui, R. and Hanamura, K. : Scanning Electron Microscopic Visualization of Bridge Formation inside the Porous Channels of Diesel Particulate Filters, SAE International Journal of Fuels and Lubricants, Vol. 9, No. 3, pp. 725-733, (2016)

(10) Srilomsak, M., Inaba, M., and Hanamura, K. : Arc generated Soot for a Comparison with Practical Diesel Soots using Characterization Analyses with a Timelapse regeneration Study on a DPF, JSAE 20199092, SAE 2019-01-2289, (2019) 